\title{
Serum metalloproteinase- 9 is related to COPD severity and symptoms - cross-sectional data from a population based cohort-study
}

Robert Linder ${ }^{1}$, Eva Rönmark², Jamshid Pourazar ${ }^{1}$, Annelie Behndig ${ }^{1}$, Anders Blomberg $^{1}$ and Anne Lindberg ${ }^{\text {** }}$

\begin{abstract}
Background: Chronic obstructive pulmonary disease, COPD, is an increasing cause of morbidity and mortality worldwide, and an imbalance between proteases and antiproteases has been implicated to play a role in COPD pathogenesis. Matrix metalloproteinases (MMP) are important proteases that along with their inhibitors, tissue inhibitors of metalloproteinases (TIMP), affect homeostasis of elastin and collagen, of importance for the structural integrity of human airways. Small observational studies indicate that these biomarkers are involved in the pathogenesis of COPD. The aim of this study was to investigate serum levels of MMP-9 and TIMP-1 in a large Swedish populationbased cohort, and their association with disease severity and important clinical symptoms of COPD such as productive cough.

Methods: Spirometry was performed and peripheral blood samples were collected in a populations-based cohort (median age 67 years) comprising subjects with COPD $(n=594)$ and without COPD $(n=948)$, in total 1542 individuals. Serum MMP-9 and TIMP-1 concentrations were measured with enzyme linked immunosorbant assay (ELISA) and related to lung function data and symptoms.

Results: Median serum MMP-9 values were significantly higher in COPD compared with non-COPD $535 \mathrm{vs.} 505 \mathrm{ng} / \mathrm{ml}$ $(P=0.017)$, without any significant differences in serum TIMP-1-levels or MMP-9/TIMP-1-ratio. In univariate analysis, productive cough and decreasing $\mathrm{FEV}_{1} \%$ predicted correlated significantly with increased MMP-9 among subjects with $\operatorname{COPD}\left(P=0.004\right.$ and $P=0.001$ respectively), and $\mathrm{FEV}_{1} \%$ predicted remained significantly associated to MMP-9 in a multivariate model adjusting for age, sex, pack years and productive cough $(P=0.033)$.

Conclusion: Productive cough and decreasing FEV 1 were each associated with MMP-9 in COPD, and decreasing FEV 1 remained significantly associated with MMP-9 also after adjustment for common confounders in this population-based COPD cohort. The increased serum MMP-9 concentrations in COPD indicate an enhanced proteolytic activity that is related to disease severity, and further longitudinal studies are important for the understanding of MMP-9 in relation to the disease process and the pathogenesis of different COPD phenotypes.
\end{abstract}

Keywords: Lung function, Productive cough, TIMP-1, MMP-9/TIMP-1 ratio, Proteases

\footnotetext{
* Correspondence: anne.lindberg@algmed.se

${ }^{1}$ Department of Public Health and Clinical Medicine, Division of Medicine,

Umeå University, SE-90187 Umeå, Sweden

Full list of author information is available at the end of the article
} 


\section{Background}

Chronic obstructive pulmonary disease, COPD, is a common chronic disease, characterised by chronic airflow limitation, recurring exacerbations and a range of pathologic changes in the lungs. COPD is described as a heterogeneous syndrome of overlapping conditions such as chronic bronchitis, emphysema and bronchiolitis [1]. Recent studies and guidelines acknowledge the importance of airway inflammation in the process of COPD development [1]. The chronic inflammatory processes in COPD leads to the loss of alveolar attachments to the small airways and decreased lung elastic recoil [2]. In turn, these changes diminish the ability of the airways to remain open during expiration, thus limiting expiratory flow.

Current hypotheses suggest that inflammation, proteaseantiprotease imbalance, oxidative stress and accelerated ageing of the lung can be accredited to the pathogenesis of COPD [3]. As part of the protease-antiprotease system, matrix metalloproteinase-9 (MMP-9) has gained an increasing research interest in COPD [4]. MMP-9 is a multi-domain enzyme with many functions in biology and pathology, among which the breakdown of collagen and gelatine is of significance in the pathogenesis of COPD [5-7]. Finding a COPD biomarker easily measured in peripheral blood, is clearly an appealing goal, especially if this biomarker would correlate with measures of disease progression.

In a study of resected human lung parenchyma from 26 patients, MMP-9 expression and the molar ratio of MMP-9 to tissue inhibitor of metalloproteinases-1 (TIMP-1) were increased in smokers compared with non-smokers, and correlated with the burden of cigarette smoking. There was also an inverse association between MMP-9 concentrations and $\mathrm{FEV}_{1} \%$ predicted values [8]. In a Swedish population-based study employing 1,016 subjects aged 70 years, the serum levels of MMP-9 were inversely associated with $\mathrm{FEV}_{1}$ without discriminating for obstructive lung function impairment. MMP-9 and TIMP-1 serum levels were also associated with smoking status, being lowest in never-smokers and highest in current smokers [9].

MMP-9 is also thought to play an important role in lung remodelling and has been investigated as a potential biomarker of COPD, given that increased elastolytic activity is a significant part of emphysema [10]. In a study comparing 23 patients with moderate to severe COPD with age-matched controls, serum MMP-9 was negatively correlated with both $\mathrm{FEV}_{1}$ and the $\mathrm{FEV}_{1} / \mathrm{FVC}$ ratio [10]. TIMP-1 is also important to consider when studying MMP-9, since it is suggested to inhibit the elastolytic activity of MMPs [11,12]. The relationship between these biomarkers and $\mathrm{FEV}_{1}$ among subjects with COPD has so far only been evaluated in fairly small observational studies, resulting in important information regarding the involvement of metalloproteinases in the pathogenesis of COPD. Besides lung function, also bronchitis symptoms and exacerbations are negative prognostic factors and related to disease severity in COPD $[13,14]$, hence important to evaluate in relation to these biomarkers. However, there is a significant under-diagnosis of COPD [15-17] and studies of population-based cohorts are therefor important in order to evaluate the significance of these biomarkers in COPD pathogenesis in general.

The aim of this population-based study was to compare serum MMP-9, TIMP-1 and MMP-9/TIMP-1 ratio in subjects with and without COPD and further to evaluate the association between these biomarkers and factors of clinical significance, such as burden of tobacco smoking, productive cough and lung function among subjects with and without COPD. The hypothesis was that the study setup with COPD subjects and nonCOPD subjects as controls would elucidate whether MMP-9 is related to COPD severity in a population based study.

\section{Methods}

\section{Participants and design}

After re-examination of four adult population cohorts from the OLIN-studies (Obstructive Lung Disease in Northern Sweden) during 2002-04, all subjects with COPD were identified together with age and gendermatched controls without obstructive lung function impairment. Since 2005 , the study population $(n=1986)$ has been annually invited to a basic examination program including spirometry and a structured interview [18].

This report is based on data from the examinations in 2005, when blood samples were collected in addition to the basic program. In 2005, 1806 out of 1915 subjects still alive (94\%) participated, whereof 164 subjects not able to attend the examinations were interviewed by telephone, 1626 subjects performed spirometry and 1621 participated in the blood sampling. The study population in this paper includes all subjects with complete data from both spirometry and blood samples $(n=1542)$. The Regional Ethics Committee at Umeå University approved the study, which was carried out according to the declaration of Helsinki.

\section{Questionnaire}

Previously well validated questions regarding respiratory symptoms were used in a structured interview [19-21]. The Modified Medical Research Council Dyspnoea Scale, mMRC, was included in the questionnaire to grade dyspnoea, scale 0-4 [22]. In addition, data on smoking habits and co-morbidities were included. 


\section{Definitions}

Body Mass Index (BMI) was calculated: weight (kg)/ (height $(\mathrm{m})^{*}$ height $(\mathrm{m})$ ) and was classified as underweight $(<20)$, normal $(20-<25)$, overweight $(25-<30)$ and obesity $(\geq 30)$.

Smoking habits were classified as: non-smokers, exsmokers (stopped since at least one year) and current smokers. Pack-years were calculated as (number of cigarettes smoked per day $\times$ number of years smoked)/20. We defined productive cough as cough and phlegm on most days for at least three months during the last 12 months. Clinically significant dyspnoea was defined as $\mathrm{mMRC}$ score $\geq 2$.

\section{Spirometry and classification of COPD}

The lung function tests were performed using a dry spirometer, Mijnhardt Vicatest 5, the Netherlands, following the ATS guidelines [23]. A reversibility test was performed if $\mathrm{FEV}_{1} /$ highest of $\mathrm{FVC}$ or $\mathrm{SVC}<0.70$, or if $\mathrm{FEV}_{1}<80 \%$ of predicted value. COPD was defined as $\mathrm{FEV}_{1}$ divided by FVC or SVC $<0.70$, using the highest value pre- or post bronchodilatation. Disease severity was classified according to the GOLD (Global Initiative for Obstructive Lung Disease) spirometric criteria based on $\mathrm{FEV}_{1} \%$ predicted; GOLD 1 - 4 [1]. Swedish spirometric reference values were used [24].

\section{Laboratory analysis}

All samples were stored since 2005 at $-20^{\circ} \mathrm{C}$, thereafter thawed and analysed at the same time. Serum concentrations of MMP-9 and TIMP-1 were assayed using the same batch of a commercially available ELISA kit (DuoSet ${ }^{\circ}$ ELISA Development System, R\&D Systems Europe Ltd., United Kingdom) according to the manufacturer's instructions. Briefly, recombinant human MMP-9 and TIMP-1 were used to construct a standard curve (range 39-2,500 pg/ml) for each set of samples assayed, serum samples were diluted 150 times and concentration read from the standard curve were multiplied by the dilution factor.

\section{Statistical analysis}

Dichotomous variables were analysed using Pearson's $\chi 2$, continuous variables with the independent variable t-test for variables that met the assumption of normal distribution, and the non-parametric Mann-Whitney U-test for those that did not. Non-normal distributed data are presented as median and interquartile range (IQR). Since there were very few subjects in GOLD 3 and 4, they were treated as one group. Univariate analyses of biomarkers (MMP-9, TIMP-1 and MMP-9/TIMP-1 ratio), stratified by COPD and non-COPD, were performed in relation to factors as sex, age, BMI-class, smoking habits, pack years, productive cough and $\mathrm{FEV}_{1} \%$ predicted. The same biomarkers were analysed in linear regression models, stratified by COPD and non-COPD, including the independent variables sex, age, pack years, productive cough and $\mathrm{FEV}_{1} \%$ predicted. The Statistical Package for the Social Sciences (SPSS) version 21.0 for Mac was used for all analyses and P-values $<0.05$ were considered significant.

\section{Results}

\section{Study population}

The basic characteristics of the study population (COPD $\mathrm{n}=594$, non-COPD $\mathrm{n}=948$ ) are presented in Table 1 . There were significant differences observed in distribution of sex, age and BMI when comparing COPD and non-COPD.

\section{Biomarkers in non-COPD and COPD as well as COPD by GOLD stage}

Median serum MMP-9 values were significantly higher in COPD compared with non-COPD, $535 \mathrm{ng} / \mathrm{ml}$ vs. $505 \mathrm{ng} / \mathrm{ml}$ $(\mathrm{p}=0.017)$, whereas there were no significant differences in serum TIMP-1-levels or MMP-9/TIMP-1-ratio (Table 1). There was a tendency towards higher MMP9-levels with higher GOLD-stage (Table 1). Figure 1 shows the association between MMP-9 values and $\mathrm{FEV}_{1} \%$ predicted in COPD by GOLD stage, each circle representing one subject, whereas Figure 2 shows the association between MMP-9/TIMP-1-ratio and FEV $\%$ predicted in COPD by GOLD stage.

\section{Univariate association with biomarkers in non-COPD and COPD}

In univariate analysis, pack years and current smoking were significantly associated with increased MMP-9 in both non-COPD and COPD. In COPD, productive cough and decreasing $\mathrm{FEV}_{1} \%$ predicted were significantly associated with increased MMP-9 (Table 2).

Corresponding analyses for TIMP-1 showed that increasing age was significantly related to increasing TIMP1 in both non-COPD and COPD (Beta: 0.122, p $<0.001$ and $0.108, p=0.009$ respectively). Increasing pack years was associated with decreasing TIMP-1 in nonCOPD(Beta: $-0.074, \mathrm{p}=0.023$ ), while current smoking was associated with decreased TIMP-1 in COPD (Beta: $-0.123, p=0.013)$. Overweight was associated with increased TIMP-1 only in COPD (Beta: 0.113, $\mathrm{p}=0.014$ ).

Increasing pack years and current smoking were associated with increasing MMP-9/TIMP-1-ratio in both non-COPD and COPD. In non-COPD increasing age was associated with a decreasing MMP-9/TIMP-1-ratio, while in COPD, overweight and decreasing $\mathrm{FEV}_{1} \%$ predicted were associated with increasing ratio (Table 3 ). 
Table 1 Study population characteristics; demographics, smoking habits, respiratory symptoms and biomarker levels, comparing non-COPD and COPD and also presented by GOLD stages

\begin{tabular}{|c|c|c|c|c|c|c|}
\hline & $\begin{array}{l}\text { Non-COPD } \\
(n=948)\end{array}$ & $\begin{array}{l}\text { COPD } \\
(n=594)\end{array}$ & P-value & $\begin{array}{l}\text { GOLD } 1 \\
(n=378)\end{array}$ & $\begin{array}{l}\text { GOLD } 2 \\
(n=190)\end{array}$ & $\begin{array}{l}\text { GOLD 3-4 } \\
(n=26)\end{array}$ \\
\hline Female, n (\%) & $447(47)$ & $248(42)$ & 0.038 & $155(41)$ & $87(46)$ & $6(23)$ \\
\hline Age (years), median (IQR) & $67(55-71)$ & $69(57-71)$ & 0.015 & $69(56-71)$ & $69(58-71)$ & $70(64-79)$ \\
\hline BMI (kg/m2), median (IQR) & $26.8(24.3-29.7)$ & $26.1(23.5-28.7)$ & $<0.001$ & $25.8(23.6-28.4)$ & $26.5(23.5-29.0)$ & $27.6(21.7-29.4)$ \\
\hline Pack years, median (IQR) & $0.8(0-12)$ & $14(0-27)$ & $<0.001$ & $8.6(0-24)$ & $18.5(2.0-32.3)$ & $26.9(14.8-42.5)$ \\
\hline Non-smoker, n (\%) & $443(47)$ & $149(25)$ & $<0.001$ & $113(30)$ & $34(18)$ & $2(8)$ \\
\hline Ex smoker, n (\%) & $384(41)$ & $247(42)$ & 0.676 & $153(40)$ & $75(41)$ & $19(73)$ \\
\hline Current smoker, n (\%) & $120(13)$ & 197 (33) & $<0.001$ & $111(29)$ & $81(43)$ & $5(19)$ \\
\hline Productive cough, n (\%) & $212(22)$ & $238(40)$ & $<0.001$ & $125(33)$ & $93(49)$ & $20(77)$ \\
\hline mMRC dyspnoea score $\geq 2, \mathrm{n}$ (\%) & $46(5)$ & $75(13)$ & $<0.001$ & $17(5)$ & $40(22)$ & $18(69)$ \\
\hline $\mathrm{FEV}_{1} \%$ predicted ${ }^{\dagger}$, median (IQR) & $1.03(0.93-1.13)$ & $0.85(0.73-0.96)$ & $<0.001$ & $0.93(0.86-1.01)$ & $0.70(0.64-0.75)$ & $0.44(0.37-0.47)$ \\
\hline MMP-9 (ng/ml), median (IQR) & $505(364-606)$ & $535(315-653)$ & 0.017 & $513(241-626)$ & $559(379-662)$ & $647(565-692)$ \\
\hline TIMP-1 (ng/ml), median (IQR) & $316(229-490)$ & $304(227-439)$ & 0.252 & $311(237-467)$ & $294(218-425)$ & $298(247-383)$ \\
\hline Ratio of MMP-9/TIMP-1, median (IQR) & $1.36(0.85-2.09)$ & $1.5(0.83-2.32)$ & 0.168 & $1.46(0.78-2.18)$ & $1.48(0.9-2.5)$ & $1.95(1.47-2.79)$ \\
\hline
\end{tabular}

$\mathrm{IQR}=$ Inter quartile range. Significant $\mathrm{p}$-values, $\mathrm{p}<0.050$, in bold.

\section{Multivariate association with biomarkers in non-COPD and COPD}

In the multivariate analyses stratified by non-COPD and COPD, MMP-9 remained significantly associated with increasing pack-years in non-COPD and decreasing $\mathrm{FEV}_{1} \%$ predicted in COPD, independent of sex, age and productive cough (Table 4). In a corresponding model, TIMP-1 was associated with increasing age in both non-COPD and COPD (Beta: 0.104, $\mathrm{p}=0.002$ and 0.102, $\mathrm{p}=0.014$ ), while in non-COPD only associated with productive cough and decreasing pack years (Beta: $0.065, \mathrm{p}=0.050$ and $-0.072, \mathrm{p}=0.034$ respectively). Similar analyses of the MMP-9/TIMP-1 ratio revealed a significant association with increasing pack years in both non-COPD and COPD, while the association with increasing age was border-line significant in non$\operatorname{COPD}(\mathrm{p}=0.051)$ as was decreasing $\mathrm{FEV}_{1} \%$ predicted in COPD $(\mathrm{p}=0.051)$ (Table 5).

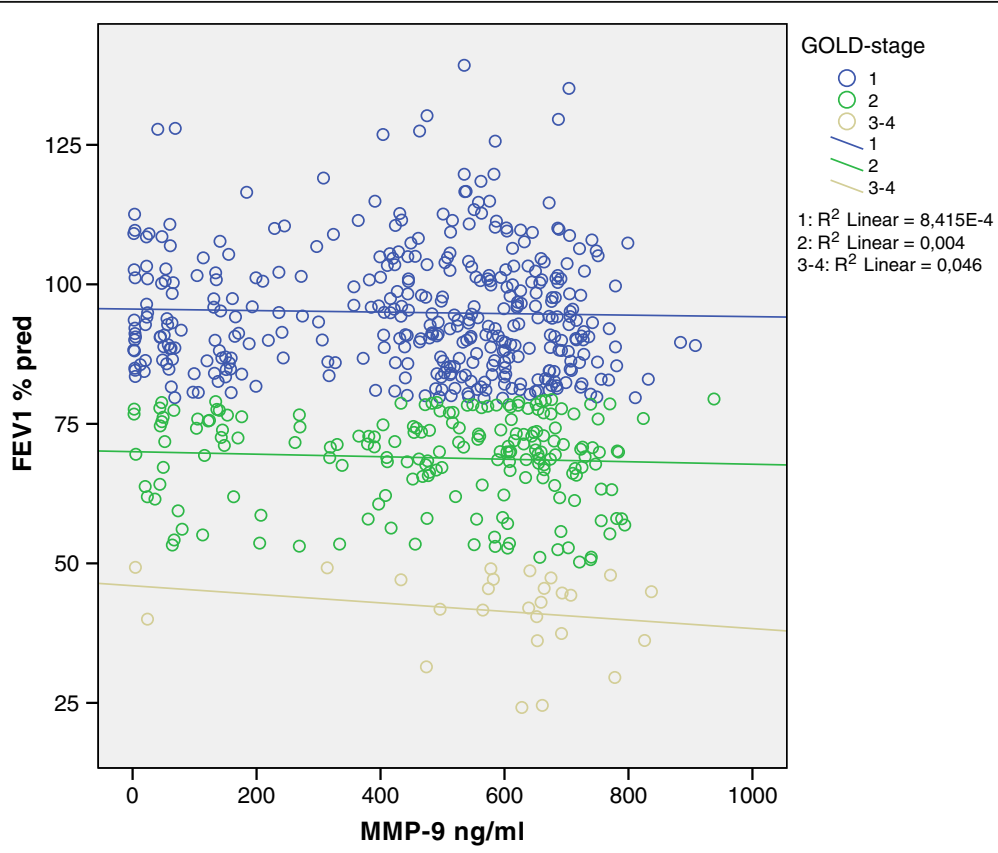

Figure 1 Association between FEV $\%$ predicted and MMP-9 in COPD subjects, the lines show the linear association between MMP-9 and $\mathrm{FEV}_{1} \%$ predicted in each GOLD stage with the $\mathrm{R}^{2}$ value indicating the strength of the association. 


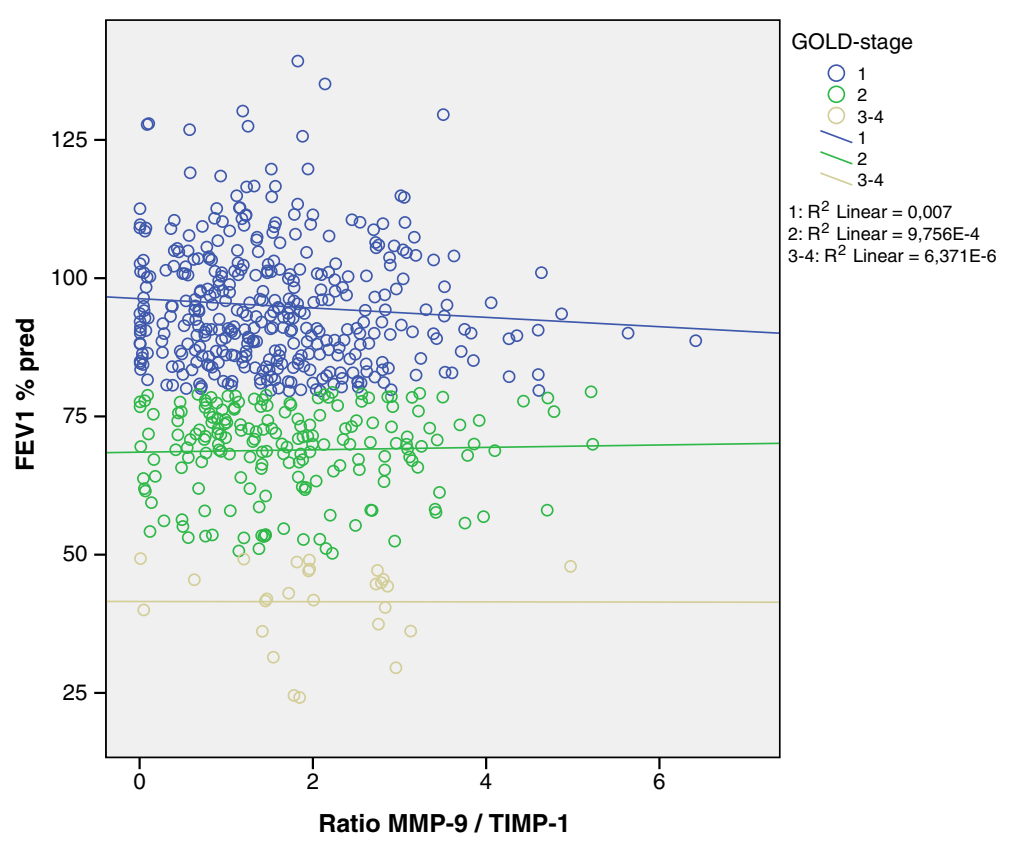

Figure 2 Association between FEV $_{1} \%$ predicted and the MMP-9/TIMP-1-ratio in COPD subjects, the lines show the linear association between MMP-9/TIMP-1-ratio and $\mathrm{FEV}_{1} \%$ predicted in each GOLD stage with the $\mathrm{R}^{2}$ value indicating the strength of the association.

Adjustments made for BMI-class, on-going or recent infection, cancer diagnosis and oral corticosteroid use did not alter main findings of the multivariate analyses.

\section{Discussion}

In this population-based study, subjects with COPD had significantly higher serum MMP-9 compared to those without obstructive lung function impairment. Among subjects with COPD, MMP-9 was significantly associated with productive cough and decreasing $\mathrm{FEV}_{1} \%$ predicted,

Table 2 Univariate analyses of associations between various factors and MMP-9 in non-COPD and COPD, respectively

\begin{tabular}{|c|c|c|c|c|}
\hline & \multicolumn{2}{|c|}{ Non-COPD } & \multicolumn{2}{|l|}{ COPD } \\
\hline & Beta & P-value & Beta & P-value \\
\hline Sex $\left(\right.$ female $\left.^{\dagger}\right)$ & -0.050 & 0.122 & -0.070 & 0.087 \\
\hline $\mathrm{Age}^{\ddagger}$ & 0.003 & 0.928 & 0.037 & 0.370 \\
\hline Underweight (normal weight ${ }^{\dagger}$ ) & 0.038 & 0.512 & -0.039 & 0.560 \\
\hline Overweight (normal weight ${ }^{\dagger}$ ) & -0.018 & 0.634 & -0.051 & 0.266 \\
\hline Obese (normal weight ${ }^{\dagger}$ ) & 0.064 & 0.155 & 0.022 & 0.706 \\
\hline Pack years ${ }^{\ddagger}$ & 0.096 & 0.003 & 0.115 & 0.005 \\
\hline Ex-smoker (non smoker ${ }^{\dagger}$ ) & -0.011 & 0.744 & 0.098 & 0.052 \\
\hline Current smoker (non smoker ${ }^{\dagger}$ ) & 0.118 & 0.005 & 0.218 & $<0.001$ \\
\hline Productive cough, pre (no $\mathrm{prc}^{\dagger}$ ) & 0.040 & 0.215 & 0.119 & 0.004 \\
\hline $\mathrm{mMRC} \geq 2\left(<2^{\dagger}\right)$ & 0.029 & 0.377 & 0.049 & 0.238 \\
\hline $\mathrm{FEV}_{1} \%$ pred $^{\ddagger}$ & -0.060 & 0.067 & -0.131 & 0.001 \\
\hline
\end{tabular}

${ }^{\dagger}$ reference value, ${ }^{\ddagger}$ continuous variable. Significant $p$-values, $p<0.050$, in bold. and in a multivariate model, decreasing $\mathrm{FEV}_{1}$ remained significantly associated with MMP-9, independent of sex, age, pack years and productive cough. In corresponding analyses among non-COPD-subjects only pack years remained significantly associated with MMP-9. Serum TIMP-1 levels were similar in COPD and nonCOPD, however, analysis of the MMP-9/TIMP-1-ratio may suggest an imbalance in the pulmonary proteaseantiprotease homeostasis among COPD-subject, with a predominance of proteolytic activity.

Table 3 Univariate analyses of associations between various factors and MMP-9/TIMP-1 ratio in non-COPD and COPD, respectively

\begin{tabular}{|c|c|c|c|c|}
\hline & \multicolumn{2}{|c|}{ Non-COPD } & \multicolumn{2}{|l|}{ COPD } \\
\hline & Beta & P-value & Beta & P-value \\
\hline Sex $\left(\right.$ female $\left.^{\dagger}\right)$ & -0.038 & 0.245 & -0.007 & 0.874 \\
\hline $\operatorname{Age}^{\ddagger}$ & -0.081 & 0.012 & -0.074 & 0.072 \\
\hline Underweight (normal weight ${ }^{\dagger}$ ) & 0.001 & 0.992 & -0.054 & 0.423 \\
\hline Overweight (normal weight ${ }^{\dagger}$ ) & -0.124 & 0.221 & -0.118 & 0.010 \\
\hline Obese (normal weight ${ }^{\dagger}$ ) & -0.009 & 0.837 & 0.202 & 0.840 \\
\hline Pack years $^{\ddagger}$ & 0.099 & 0.002 & 0.124 & 0.003 \\
\hline Ex-smoker (non smoker ${ }^{\dagger}$ ) & 0.045 & 0.195 & 0.102 & 0.043 \\
\hline Current smoker (non smoker ${ }^{\dagger}$ ) & 0.106 & 0.011 & 0.256 & $<0.001$ \\
\hline Productive cough, $\operatorname{prc}\left(\right.$ no $\left.\mathrm{prc}^{\dagger}\right)$ & 0.004 & 0.904 & 0.060 & 0.148 \\
\hline $\operatorname{mMRC} \geq 2\left(<2^{\dagger}\right)$ & 0.003 & 0.929 & 0.034 & 0.424 \\
\hline $\mathrm{FEV}_{1} \%$ pred $^{\ddagger}$ & -0.040 & 0.219 & -0.118 & 0.004 \\
\hline
\end{tabular}

${ }^{\dagger}$ reference value, ${ }^{\ddagger}$ continuous variable. Significant $p$-values, $p<0.050$, in bold. 
Table 4 Multivariate analyses of factors associated with MMP-9 in in non-COPD and COPD, respectively

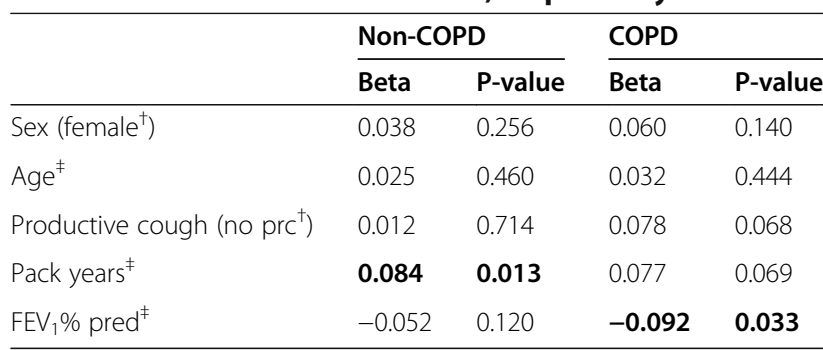

${ }^{{ }}$reference value, ${ }^{\ddagger}$ continuous variable. Significant $\mathrm{p}$-values, $\mathrm{p}<0.050$, in bold.

An association between smoking and MMP-9 has been shown previously $[8,9,25]$. In the present univariate analyses, current smoking was associated with MMP-9 as well as increased MMP-9/TIMP-1 ratio, suggesting that smoking per se increases the proteolytic activity in both COPD and non-COPD. In this context, it deserves to be mentioned that the effect of smoking on MMP-9 may, at least in sputum, remain at least 6 months after smoking cessation [26]. Furthermore, the burden of tobacco smoke exposure, assessed as pack years, was associated with increasing MMP-9/TIMP-1-ratio in both COPD and non-COPD, indicating a tobacco smoke-induced increase in proteolytic activity, independent of sex, age and $\mathrm{FEV}_{1}$. According to a recently published study of 80 women with COPD and 40 controls, not only smoking, but also exposure to biomass combustion, was related to differences in metalloproteinases, including increased MMP-9 and MMP-9/TIMP-1 ratio, among those with COPD [27].

Small observational studies have demonstrated increased MMP-9 in COPD compared to controls, both in analyses of sputum [28], lung parenchyma [8] and serum [10]. To the best of our knowledge, this is the first study, in which serum-MMP-9 has been analysed and also proven to be increased in a population-based COPDcohort. Furthermore, the association between serum MMP-9 and impaired lung function, assessed as $\mathrm{FEV}_{1}$, in COPD show that MMP-9 is related to disease severity which could indicate that MMP-9 is involved in the disease process in COPD. TIMP-1 is suggested to inhibit

Table 5 Multivariate analyses of factors associated with MMP-9/TIMP-1 ratio in non-COPD and COPD, respectively

\begin{tabular}{|c|c|c|c|c|}
\hline & \multicolumn{2}{|c|}{ Non-COPD } & \multicolumn{2}{|l|}{ COPD } \\
\hline & Beta & P-value & Beta & P-value \\
\hline Sex $\left(\right.$ female $\left.{ }^{\dagger}\right)$ & 0.021 & 0.534 & -0.007 & 0.856 \\
\hline $\mathrm{Age}^{\ddagger}$ & -0.065 & 0.051 & -0.075 & 0.071 \\
\hline Productive cough (no $\mathrm{prc}^{\dagger}$ ) & -0.009 & 0.796 & 0.036 & 0.400 \\
\hline Pack years ${ }^{\ddagger}$ & 0.088 & 0.010 & 0.095 & 0.027 \\
\hline $\mathrm{FEV}_{1} \%$ pred $^{\ddagger}$ & -0.020 & 0.553 & -0.084 & 0.051 \\
\hline
\end{tabular}

${ }^{\dagger}$ reference value, ${ }^{\ddagger}$ continuous variable. Significant $p$-values, $p<0.050$, in bold. the proteolytic activity of MMPs [11,12], and the observed association between overweight and TIMP-1 may imply a protecting mechanism by overweight in COPD. We also confirmed, as previously shown [29,30], that serum TIMP-1 is associated with age. The MMP-9/ TIMP-1 ratio was analysed in order to evaluate the protease-antiprotease imbalance of possible importance in the pathogenesis of COPD and, besides increasing pack years, decreasing $\mathrm{FEV}_{1} \%$ predicted was close to significantly related to the ratio.

Chronic bronchitis is a well-known predictor of accelerated lung function decline and increased risk for exacerbations in COPD [31,32]. Also less longstanding bronchitis symptoms, such as productive cough, seem to be an important prognostic marker in COPD, accelerating the rate of decline in lung function [33], increasing the risk for exacerbations [34] and mortality [33]. In a cohort of 100 COPD-patients recruited from outpatient care, sputum MMP-9 levels were associated with the proportion of sputum neutrophils, independent of age, prior smoking and presence of airflow obstruction [28]. We found a positive association between productive cough and serum MMP-9 in COPD, indicating increased proteolytic activity in COPD patients with bronchitis, even though this association did not reach statistical significance in the multivariate model. Today, COPD is considered an inflammatory lung disease with systemic effects which, in the western society, is caused primarily by tobacco smoke exposure $[28,35]$ and a populationbased study will include subjects with different clinical manifestations or phenotypes of COPD. In the present population-based study, the observed biomarker signals are thus important to note, as they are clearly hypothesis-generating for further studies. The association between increased MMP-9 and productive cough among subjects with COPD shown here contribute, together with previous reports from selected study populations [9,36,37], to the hypothesis that MMP-9 may be involved in the disease process in COPD-subjects with bronchitis symptoms and a history of frequent exacerbations, or the 'exacerbating-bronchitis' phenotype [38]. However, in a cross-sectional study such as ours, only associations can be evaluated and longitudinal studies are important for the understanding of MMP-9 and TIMP-1 in relation to measures of disease progression and pathogenesis of different phenotypes of COPD.

Other clinical manifestations of COPD to which MMP-9 may be of importance in the pathogenesis are emphysema and rapid decline in lung function. It has previously been suggested that MMP-9 is related to the development of emphysema [39-41]. In a one-year follow up of 126 patients with the more homogenous phenotype of COPD related to alpha ${ }_{1}$-antitrypsin deficiency, plasma MMP-9 was associated not only with 
more frequent exacerbations, but also with a decline in transfer factor and a reduction in lung density assessed by CT scan (computer tomography) [35]. In several studies including COPD populations with different clinical phenotypes, MMP-9 has been related to lower lung function $[10,27,35,42]$ and, in our study, we have shown that the relationship between MMP-9 and lower lung function, assessed as $\mathrm{FEV}_{1} \%$ predicted, also applies to COPD in a population-based cohort, dominated by mild to moderate disease; GOLD stages 1-2.

Assessment of COPD disease severity is most often based on the GOLD spirometric classification divided into stages 1-4 [1]. Each stage includes rather wide ranges of $\mathrm{FEV}_{1} \%$ predicted and, thus, the use of $\mathrm{FEV}_{1} \%$ predicted, as a continuous variable, may be more sensitive when it comes to evaluating biomarkers related to disease severity. Our results illustrated this phenomenon fairly well, as decreasing $\mathrm{FEV}_{1} \%$ predicted, but not GOLD stages, was associated with MMP-9 and MMP-9/ TIMP-1 ratio among subjects with COPD. In epidemiological studies identifying COPD by spirometry, the GOLD 1 group will include a non-negligible proportion of non-smokers without respiratory symptoms, especially among elderly [43]. Thus the GOLD 1 group may include some "noise" that has to be taken into account when interpreting data.

The strength of this study is the large populationbased COPD cohort identified by standardized spirometry, and with a distribution of disease severity conforming well to other population-based studies $[9,44]$. Thus, both the internal and external validity are considered good, and the study contributes with novel data that imply that MMP-9 is related to disease severity and symptoms in not only selected COPD populations but also population-based cohorts. However, there are also limitations of the study that merit some discussion. First, the ELISA used to measure the levels of MMP-9 and TIMP-1, include both total and pro-enzyme levels. Second, it has been suggested that serum MMP-9 levels do not reflect overall MMP-9 airway activity, as COPD is associated with higher levels of MMP-9 but not with increased MMP-9 activity. Further, the samples were stored several years before the analyses were performed, and it has been shown that the level of these biomarkers decrease by time [45]. However, the geometric decrease in measurable enzyme should be the same for all samples; half-life for degradation is identical for a single enzyme and the possible effects of storage are expected to affect all samples in an equivalent manner. We can exclude another potential source of error, namely the use of different ELISA-kit-batches when performing analyses at different time-points. Thus the measured absolute values may be influenced by storage, but not likely the results, regarding the observed correlations. In the present study, the MMP-9/TIMP-1 ratio was calculated based on the concentrations. This way of addressing the systemic protease-anti-protease balance has been employed in a number of recent studies $[43,46,47]$. A biologically more relevant way of estimating the proteolytic balance may also include the molar MMP-9/ TIMP-1-ratio that has been used in some studies [43]. However, as only the total MMP-9 concentration was determined here, no data on active MMP-9 are available and, hence, a relevant molar ratio cannot be calculated. This fact is a limitation of the study and analyses of both the active and total MMP-9 concentrations and their relation to TIMP-1 are warranted in future studies.

Another factor to be considered is that the fixed ratio of $\left(\mathrm{FEV}_{1} / \mathrm{FVC}<0.70\right)$ carries a risk of COPD overdiagnosis in elderly and of under-diagnosis in younger [43]. However, the OLIN COPD study was designed after the shift of the millennium just after the launch of the GOLD guidelines recommending this fixed ratio for the definition of airway obstruction. If a similar epidemiological study were to be designed today, the LLN (lower limit of normal) definition of airway obstruction would be considered.

\section{Conclusion}

This is the first population-based cross-sectional study analysing and demonstrating that serum MMP-9 is higher in COPD compared with in non-COPD. Productive cough and decreasing $\mathrm{FEV}_{1}$ were each associated with MMP-9 among subjects with COPD, and decreasing $\mathrm{FEV}_{1}$ remained significantly associated with MMP-9 also after adjustment for common confounders in this population-based COPD cohort. The MMP-9/TIMP-1ratio may suggest an imbalance in the pulmonary protease-antiprotease homeostasis in COPD, with a predominance of proteolytic activity that is related to impaired lung function and, thus, disease severity. Future longitudinal studies are important for the further understanding of MMP-9 and TIMP-1 in relation to disease progress and the pathogenesis of different COPD phenotypes.

\section{Competing interests}

The authors declare that they have no competing interests.

\section{Authors' contributions}

$\mathrm{RL}$ performed the statistical analysis drafting and writing the manuscript. ER participated in the design of the study and writing the manuscript. JP carried out the immunoassays, and wrote part of the manuscript. AFB participated in writing the manuscript. $A B$ participated in drafting and writing the manuscript. $A L$, corresponding author, participated in the design of the study, drafting and writing the manuscript. All authors have read and approved the final manuscript.

\section{Acknowledgement}

The Swedish Heart-Lung Foundation, Umeå University, Norrbotten and Västerbotten county councils funded the study. 
The authors acknowledge Bo Lundbäck, the founder of the OLIN-studies and initiator of the OLIN COPD-study. The authors thank Helena Backman and Hans Stenberg for statistical support, and Ann-Christin Jonsson, Sigrid Sundberg and Linnea Hedman for data collection.

\section{Author details}

'Department of Public Health and Clinical Medicine, Division of Medicine, Umeå University, SE-90187 Umeå, Sweden. ${ }^{2}$ Department of Public Health and Clinical Medicine, the OLIN unit, Division of Occupational and Environmental Medicine, Umeå, University, "SE-90187, Umeå, Sweden.

Received: 22 November 2014 Accepted: 4 February 2015 Published online: 21 February 2015

\section{References}

1. Vestbo J, Hurd SS, Agusti AG, Jones PW, Vogelmeier C, Anzueto A, et al. Global strategy for the diagnosis, management, and prevention of chronic obstructive pulmonary disease. Am J Respir Crit Care Med. 2013;187:347-65.

2. Hogg JC, Chu F, Utokaparch S, Woods R, Elliott WM, Buzatu L, et al. The nature of small-airway obstruction in chronic obstructive pulmonary disease. N Engl J Med. 2004;350:2645-53.

3. Fischer BM, Pavlisko E, Voynow JA. Pathogenic triad in COPD: oxidative stress, protease-antiprotease imbalance, and inflammation. COPD. 2011;6:413-21.

4. Chen L, Wang T, Liu L, Shen Y, Wan C, Wen F. Matrix metalloproteinase-91562C/T promoter polymorphism confers risk for COPD: a meta-analysis. PLoS One. 2013;8:e60523.

5. Vandooren J, Van den Steen PE, Opdenakker G. Biochemistry and molecular biology of gelatinase $B$ or matrix metalloproteinase-9 (MMP-9): The next decade. Crit Rev Biochem Mol Biol. 2013:48:222-72.

6. Cauwe B, Opdenakker G. Intracellular substrate cleavage: a novel dimension in the biochemistry, biology and pathology of matrix metalloproteinases. Crit Rev Biochem Mol Biol. 2010;45:351-423.

7. Churg A, Wright JL. Proteases and emphysema. Curr Opin Pulm Med. 2005;11:153.

8. Kang MJ, Oh Y-M, Lee JC, Kim DG, Park MJ, Lee MG, et al. Lung matrix metalloproteinase-9 correlates with cigarette smoking and obstruction of airflow. J Korean Med Sci. 2003;18:821-7.

9. Olafsdóttir IS, Janson C, Lind L, Hulthe J, Gunnbjörnsdóttir M, Sundström J. Serum levels of matrix metalloproteinase-9, tissue inhibitors of metalloproteinase-1 and their ratio are associated with impaired lung function in the elderly: a population-based study. Respirology. 2010;15:530-5.

10. Brajer B, Batura-Gabryel H, Nowicka A, Kuznar-Kaminska B, Szczepanik A. Concentration of matrix metalloproteinase-9 in serum of patients with chronic obstructive pulmonary disease and a degree of airway obstruction and disease progression. J Physiol Pharmacol. 2008:59:145-52.

11. Beeh KM, Beier J, Kornmann O, Buhl R. Sputum matrix metalloproteinase-9, tissue inhibitor of metalloprotinease-1, and their molar ratio in patients with chronic obstructive pulmonary disease, idiopathic pulmonary fibrosis and healthy subjects. Respir Med. 2003;97:634-9.

12. Cataldo D, Munaut C, Noël A, Frankenne F, Bartsch P, Foidart JM, et al. MMP-2- and MMP-9-linked gelatinolytic activity in the sputum from patients with asthma and chronic obstructive pulmonary disease. Int Arch Allergy Immunol. 2000;123:259-67.

13. Vestbo J, Prescott E, Lange P. Association of chronic mucus hypersecretion with FEV1 decline and chronic obstructive pulmonary disease morbidity. Copenhagen City Heart Study Group. Am J Respir Crit Care Med. 1996;153:1530-5.

14. Connors AFA, Connors AFA, Dawson NVN, Dawson NVN, Thomas CC, Thomas CC, et al. Outcomes following acute exacerbation of severe chronic obstructive lung disease. The SUPPORT investigators (Study to Understand Prognoses and Preferences for Outcomes and Risks of Treatments). Am J Respir Crit Care Med. 1996;154:959-67.

15. Lindberg A, Bjerg A, Bjerg-Bäcklund A, Rönmark E, Larsson L-G, Lundbäck B. Prevalence and underdiagnosis of COPD by disease severity and the attributable fraction of smoking report from the obstructive lung disease in Northern Sweden studies. Respir Med. 2006;100:264-72.

16. Halbert RJ, Natoli JL, Gano A, Badamgarav E, Buist AS, Mannino DM. Global burden of COPD: systematic review and meta-analysis. Eur Respir $\mathrm{J}$. 2006;28:523-32.
17. Danielsson P, Ólafsdóttir IS, Benediktsdóttir B, Gíslason T, Janson C. The prevalence of chronic obstructive pulmonary disease in Uppsala, Swedenthe burden of obstructive lung disease (BOLD) study: cross-sectional population-based study. Clin Respir J. 2012;6:120-7.

18. Lindberg A, Lundbäck B. The obstructive lung disease in northern sweden chronic obstructive pulmonary disease study: design, the first year participation and mortality. Clin Respir J. 2008;2 Suppl 1:64-71.

19. Lundbäck B, Stjernberg N, Nystrom L, Forsberg B, Lindström M, Lundbäck K, et al. Epidemiology of respiratory symptoms, lung function and important determinants: Report from the obstructive lung disease in northern Sweden project. Tuber Lung Dis. 1994;75:116-26.

20. Pallasaho $P$, Lundbäck B, Läspä SL, Jönsson $E$, Kotaniemi J, Sovijärvi ARA, et al. Increasing prevalence of asthma but not of chronic bronchitis in Finland? Report from the FinEsS-Helsinki study. Respir Med. 1999;93:798-809.

21. Lundbäck B, Eriksson B, Lindberg A, Ekerljung L, Muellerova H, Larsson L-G, et al. A 20-year follow-up of a population study-based COPD cohort-report from the obstructive lung disease in Northern Sweden studies. COPD. 2009;6:263-71.

22. Mahler DA, Wells CK. Evaluation of clinical methods for rating dyspnea. Chest. 1988;93:580-6.

23. Standardization of Spirometry, 1994 Update. American Thoracic Society. Am J Respir Crit Care Med 1995 Sep;152(3):1107-36

24. Berglund E, Birath G, Bjure J, Grimby G, Kjellmer I, Sandqvist L, et al. Spirometric studies in normal subjects. I. Forced expirograms in subjects between 7 and 70 years of age. Acta Med Scand. 1963;173:185-92.

25. Ilumets H, Mazur W, Toljamo T, Louhelainen N, Nieminen P, Kobayashi H, et al. Ageing and smoking contribute to plasma surfactant proteins and protease imbalance with correlations to airway obstruction. BMC Pulm Med. 2011;11:19.

26. Louhelainen N, Stark H, Mazur W, Rytilä P, Djukanovic R, Kinnula VL. Elevation of sputum matrix metalloproteinase-9 persists up to 6 months after smoking cessation: a research study. BMC Pulm Med. 2010;10:13.

27. Montaño M, Sansores RH, Becerril C, Cisneros J, González-Avila G, Sommer $B$, et al. FEV1 inversely correlates with metalloproteinases 1, 7, 9 and CRP in COPD by biomass smoke exposure. Respir Res. 2014;15:74.

28. Simpson JL, McDonald VM, Baines KJ, Oreo KM, Wang F, Hansbro PM, et al. Influence of age, past smoking, and disease severity on TLR2, neutrophilic inflammation, and MMP-9 levels in COPD. Med Inflamm. 2013;2013:462934.

29. Oblak I, Anderluh F, Velenik V, Mozina B, Ocvirk J, Ciric E, et al. Differences in plasma TIMP-1 levels between healthy people and patients with rectal cancer stage II or III. Radiol Oncol. 2011;45:209-12.

30. Holten-Andersen MN, Murphy G, Nielsen HJ, Pedersen AN, Christensen IJ, Høyer-Hansen G, et al. Quantitation of TIMP-1 in plasma of healthy blood donors and patients with advanced cancer. Br J Cancer. 1999;80:495-503.

31. Burgel P-R, Paillasseur J-L, Caillaud D, Tillie-Leblond I, Chanez P, Escamilla R, et al. Clinical COPD phenotypes: a novel approach using principal component and cluster analyses. Eur Respir J. 2010;36:531-9.

32. Snoeck-Stroband JB, Lapperre TS, Gosman MME, Boezen HM, Timens W, HackenTen NHT, et al. Chronic bronchitis sub-phenotype within COPD: inflammation in sputum and biopsies. Eur Respir J. 2008;31:70-7.

33. Putcha N, Drummond MB, Connett JE, Scanlon PD, Tashkin DP, Hansel NN, et al. Chronic productive cough is associated with death in smokers with early COPD. COPD. 2014;11:451-8.

34. Miravitlles M. Cough and sputum production as risk factors for poor outcomes in patients with COPD. Respir Med. 2011;105:1118-28.

35. Omachi TA, Omachi TA, Eisner MD, Eisner MD, Rames A, Rames A, et al. Matrix metalloproteinase-9 predicts pulmonary status declines in a1antitrypsin deficiency. Respir Res. 2010;12:35-5.

36. Navratilova Z, Zatloukal J, Kriegova E, Kolek V, Petrek M. Simultaneous upregulation of matrix metalloproteinases $1,2,3,7,8,9$ and tissue inhibitors of metalloproteinases 1, 4 in serum of patients with chronic obstructive pulmonary disease. Respirology. 2012;17:1006-12.

37. Higashimoto Y, Iwata T, Okada M, Satoh H, Fukuda K, Tohda Y. Serum biomarkers as predictors of lung function decline in chronic obstructive pulmonary disease. Respir Med. 2009;103:1231-8.

38. Friedlander AL, Lynch D, Dyar LA, Bowler RP. Phenotypes of chronic obstructive pulmonary disease. COPD. 2007;4:355-84.

39. Churg A, Zhou S, Wright JL. Series "matrix metalloproteinases in lung health and disease": matrix metalloproteinases in COPD. Eur Respir J. 2012;39:197-209.

40. Trocme C, Deffert C, Cachat J, Donati Y, Tissot C, Papacatzis S, et al. Macrophage-specific NOX2 contributes to the development of lung 
emphysema through modulation of SIRT1/MMP-9 pathways. Pathol. 2015;235(1):65-78. doi:10.1002/path.4423.

41. Bruun CS, Jensen LK, Leifsson PS, Nielsen J, Cirera S, Jørgensen CB, et al. Functional characterization of a porcine emphysema model. Lung. 2013;191:669-75.

42. Kanner RE, Anthonisen NR, Connett JE. Lower respiratory illnesses promote FEV1 decline in current smokers but Not Ex-smokers with mild chronic obstructive pulmonary disease. Am J Respir Crit Care Med. 2001;164:358-64.

43. Hardie V, Bakke, Morkve. Respiratory symptoms and obstructive pulmonary disease in a population aged over 70 years. Respir Med. 2005;99:10-0.

44. Bourbeau J, Tan WC, Benedetti A, Aaron SD, Chapman KR, Coxson HO, et al. Canadian Cohort Obstructive Lung Disease (CanCOLD): fulfilling the need for longitudinal observational studies in COPD. COPD. 2014;11:125-32.

45. Rouy D, Ernens I, Jeanty C, Wagner DR. Plasma storage at -80 degrees $C$ does not protect matrix metalloproteinase-9 from degradation. Anal Biochem. 2005;338:294-8.

46. Kong MYF, Clancy JP, Peng N, Li Y, Szul TJ, Xu X, et al. Pulmonary matrix metalloproteinase-9 activity in mechanically ventilated children with respiratory syncytial virus. Eur Respir J. 2014;43:1086-96

47. Lorente L, Martín MM, Solé-Violán J, Blanquer J, Labarta L, Díaz C, et al. Association of sepsis-related mortality with early increase of TIMP-1/MMP-9 ratio. PLoS One. 2014;9:e94318.

\section{Submit your next manuscript to BioMed Central and take full advantage of:}

- Convenient online submission

- Thorough peer review

- No space constraints or color figure charges

- Immediate publication on acceptance

- Inclusion in PubMed, CAS, Scopus and Google Scholar

- Research which is freely available for redistribution 